\title{
Butterfly Learning and the Diversification of Plant Leaf Shape
}

\author{
Denise D. Dell'Aglio ${ }^{1,2 *}$, María E. Losada ${ }^{2}$ and Chris D. Jiggins ${ }^{1,2}$ \\ 'Butterfly Genetics Group, Department of Zoology, University of Cambridge, Cambridge, UK, ${ }^{2}$ Smithsonian Tropical \\ Research Institute, Panama City, Panama
}

Visual cues are important for insects to find flowers and host plants. It has been proposed that the diversity of leaf shape in Passiflora vines could be a result of negative frequency dependent selection driven by visual searching behavior among their butterfly herbivores. Here we tested the hypothesis that Heliconius butterflies use leaf shape as a cue to initiate approach toward a host plant. We first tested for the ability to recognize shapes using a food reward conditioning experiment. Butterflies showed an innate preference for flowers with three and five petals. However, they could be trained to increase the frequency of visits to a non-preferred flower with two petals, indicating an ability to learn to associate shape with a reward. Next we investigated shape learning specifically in the context of oviposition by conditioning females to lay eggs on two shoots associated with different artificial leaf shapes: their own host plant, Passiflora biflora, and a lanceolate non-biflora leaf shape. The conditioning treatment had a significant effect on the approach of butterflies to the two leaf shapes, consistent with a role for shape learning in oviposition

OPEN ACCESS

Edited by:

Peter Schausberger,

University of Vienna, Austria

Reviewed by:

Emilie Snell-Rood,

University of Minnesota, USA

Martha Weiss,

Georgetown University, USA

*Correspondence: Denise D. Dell'Aglio ddd23@cam.ac.uk

Specialty section:

This article was submitted to Behavioral and Evolutionary Ecology, a section of the journal

Frontiers in Ecology and Evolution

Received: 27 April 2016

Accepted: 17 June 2016

Published: 28 July 2016

Citation:

Dell'Aglio DD, Losada ME and Jiggins CD (2016) Butterfly Learning and the Diversification of Plant Leaf

Shape. Front. Ecol. Evol. 4:81.

doi: 10.3389/fevo.2016.00081 behavior. This study is the first to show that Heliconius butterflies use shape as a cue for feeding and oviposition, and can learn shape preference for both flowers and leaves. This demonstrates the potential for Heliconius to drive negative frequency dependent selection on the leaf shape of their Passiflora host plants.

Keywords: leaf shape, flower shape, host selection, oviposition, Passiflora, Heliconius

\section{INTRODUCTION}

Co-evolution between plants and herbivores is a major cause of both plant and insect diversity and adaptation (Ehrlich and Raven, 1964). The role of host shifts and key innovations as a driving force in herbivore diversification has been widely studied. Similarly, in recent years there has been considerable interest in the role of herbivores in promoting plant diversification, specifically through the Janzen-Connell effect (Janzen, 1970; Connell, 1971). This hypothesis states that herbivores could exert negative frequency dependent selection by adapting to exploit the commonest host plants in their local environment. This could in turn favor rare plant species and promote local plant species diversity.

The Janzen-Connell hypothesis has generally been discussed in the context of specialist herbivores preventing the local establishment of common plant species. However, an alternative mechanism is that more generalist herbivores might learn a "search image" for locally common plant species. This could similarly generate negative frequency dependence, but on a much shorter timescale (Sinervo and Calsbeek, 2006). In visually searching predators, this could be driven by learning of distinctive cues for finding host plants, such as leaf shape. Variation in the size and shape of leaves is often considered to be mainly a result of the physiological and biomechanical demands imposed by different habitats (Brown et al., 1991). The role of herbivores in influencing 
the evolution of leaf size and shape has mainly considered in the context of physical barriers to herbivory (Brown et al., 1991). The role of leaf shape as an adaptation against visual herbivores has been less well studied, but one example is leaf mimicry in the Boquila trifoliolata vine, which mimics the leaves of its supporting trees to avoid visual herbivores (Gianoli and Carrasco-Urra, 2014).

In order to test the idea that herbivores might use visual cues such as leaf shape in finding their host plants, we need to demonstrate that the relevant herbivores can indeed use shape cues. Shape perception in insects has primarily been studied from the perspective of foraging bees (Anderson, 1977; Zhang et al., 1995), which show a preference for radial patterns when searching for nectar (Lehrer et al., 1995). Monarch butterflies, Danaus plexippus, are capable of learning shape only in association with color, showing that both stimuli must appear together in the context of foraging for nectar (Cepero et al., 2015). Furthermore, leaf shape detection and learning has been demonstrated in oviposition preference in Battus philenor (Rausher, 1978; Rausher and Papaj, 1983; Papaj, 1986; Weiss and Papaj, 2003) and in Eurema, which landed more often on leaves that resemble their host (Mackay and Jones, 1989).

Perhaps the most promising system in which visually searching herbivores interact with a diverse community of leaf shapes is among Heliconius butterflies and their Passiflora host plants (Gilbert, 1982). Leaf morphology in the family Passifloraceae, both between and within species, is among the most variable observed in any plant group (Figure 1A). In any locality, Passiflora species exhibit a wide variety of leaf shapes even if they are closely related and inhabit similar physical conditions (Benson et al., 1975; Gilbert, 1975, 1982). Some species also show a huge range of intra-specific variation in shapes, especially between young and old leaves (Gilbert, 1982). For example, Passiflora suberosa shows a high degree of leaf plasticity when raised in different light intensities (Barp et al., 2006). In addition, some Passiflora are very similar in form and texture to other non-host plants, which might be a form of mimicry. Gilbert (1975) speculated that visual searching behavior by Heliconius butterflies acts as a diversifying evolutionary force on Passiflora vines. Heliconius larvae feed almost exclusively on the family Passifloraceae, and can cause severe foliage damage (Gilbert, 1982). This close insect-plant interaction has led to the evolution of various defense mechanisms in Passiflora plants in response to selective forces imposed by Heliconius caterpillars.

The Heliconius-Passiflora interaction is already well established as an example of insect-host co-evolution. Passiflora species possess a range of defensive traits, such as production of chemical compounds that provide feeding barriers (Smiley, 1985a; Engler et al., 2000) and mechanical protection such as hooked trichomes that are able to pierce larvae, resulting in death for the majority of Heliconius caterpillars on P. adenopoda (Gilbert, 1971). In turn Heliconius charithonia has evolved to overcome these trichomes and is the only species that can feed on this host. In addition, extra-floral nectaries on some Passiflora species are similar to Heliconius eggs (Gilbert, 1982).

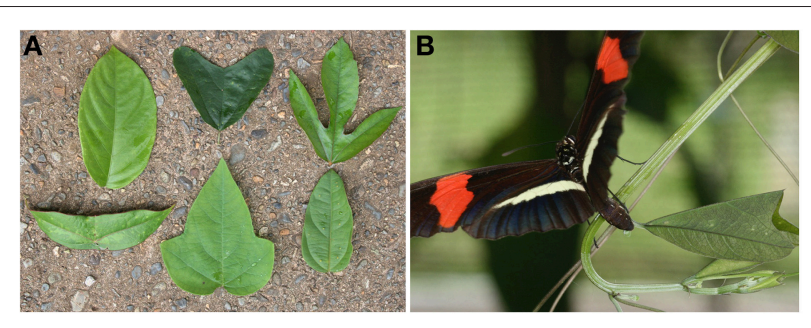

FIGURE 1 | Passiflora species that occur in Gamboa or nearby Soberanía National Park, Panama, highly differ in leaf morphology. (A) From left to right: top, P. ambigua, P. biflora, P. edulis; bottom, P. coriacea, P. menispermifolia, $P$. auriculata. (B) Heliconius erato petiverana female laying egg on a $P$. biflora shoot.

In Passiflora cyanea projections on the stipules resemble, in shape and color, eggs of Heliconius ethilla (Williams and Gilbert, 1981). Females avoid ovipositing in the presence of a conspecific egg on the host, as young larvae are often cannibalistic (Nardin and Araújo, 2011), and are therefore deterred by these egg mimics. Egg-mimicry of extra-floral nectaries provides strong evidence that ovipositing females use visual cues in the selection of suitable Passiflora vines. Another function of extra-floral nectaries against herbivores is the production of nectar that attracts ants to the plant, to collect this valuable food resource (Apple and Feener, 2001; Izaguirre et al., 2013). Ants in turn attack Heliconius larvae and eggs (Smiley, 1985b, 1986).

Based on field observations, females of Heliconius butterflies use visual cues while searching for host plants (Brown, 1981). Females may inspect objects that resemble a Passiflora structure, such as similarly shaped leaves or vines that look like tendrils (Benson et al., 1975; Gilbert, 1982). A female searching for a specific Passiflora plant typically flutters slowly just above the vegetation, periodically approaching, and landing on leaves (Figure 1B). Upon landing, she drums her forelegs and presumably stimulates tarsal chemoreceptors, allowing the female to "taste" the plant with her gustatory receptors (Briscoe et al., 2013). It has been hypothesized that Passiflora leaf shape variation might make it harder for Heliconius females to detect host plants.

However, shape detection has not yet been demonstrated in Heliconius butterflies. They can be trained to associate a color stimulus with a food reward, demonstrating a high precision of discrimination and learning (Swihart and Swihart, 1970; Swihart, 1971; Blackiston et al., 2011). Here we extend these experiments to show that Heliconius erato can be trained to associate a shape cue with a food reward, demonstrating the perceptual ability to detect and distinguish shapes. Next, we tested shape perception for leaf morphology using ovipositing females trained on artificial leaves. $H$. erato naturally feeds on three species with diverse leaf shapes in our study area, and our results show that learnt shape preference is therefore a plausible selective force on Passiflora leaf morphology in this community. 


\section{MATERIALS AND METHODS}

\section{Butterfly Rearing}

Experiments were performed between March 2014 and August 2015 in insectary facilities located in Gamboa, Panama. Wild adults of $H$. erato Linnaeus, 1758 were caught in the surrounding areas and kept in insectary cages for egg collection. Caterpillars were reared on Passiflora biflora Lam. leaves. Adults were fed with sugar solution and pollen from Psiguria sp. flowers and were around maximum 2 weeks old at the beginning of the training period.

\section{Flower Shape Experiment}

This experiment was designed to test whether Heliconius butterflies can perceive shapes using a learning experiment with a food reward. As shapes are defined in terms of the luminance contrast at their boundaries against the background (Zhang et al., 1995), five flower shapes were chosen varying the number of petals (zero, two, three, four, and five, Figure 2), generating marked differences in the shape edges and perimeter. Artificial flowers were constructed of red foam sheets (ethylene-vinyl acetate) with a $1 \mathrm{ml}$ Eppendorf tube for sugar water solution attached in the center. The color red was chosen to facilitate association of model flowers with food, because most of the flowers used by Heliconius have this coloration (Estrada and Jiggins, 2002). Prior to the experiment adult butterflies were fed with a sugar solution presented in feeders made of red card to increase the association of color and food. Butterflies were subjected to over-night food deprivation to ensure they would be willing to feed. Groups of five to six butterflies were separated in a different cage for the experiment, both females and males.

The first part of this experiment was designed to demonstrate spontaneous feeding preferences and to determine innate choice of flower shapes. A set of five shapes was presented, none of which contained a food reward. The relative position of flowers was randomized. The first choice of flower, and the number of feeding attempts in which the butterfly landed on the artificial flower and probed with its proboscis were recorded for $30 \mathrm{~min}$. Over the following 8 days, butterflies were presented with the least preferred shape from the first trial (the two-petal shape) with sugar solution, while the other shapes contained only water. The shape choice trial was then repeated by again presenting the set of five shapes without a food reward, using the same method described above. We aimed to determine whether feeding experience could modify initial feeding preferences through learning. All experiments were performed in the early morning when butterflies were active and willing to feed and the experimental flowers provided the first food source of the day. After the experiments, butterflies were allowed to feed on Psiguria sp. flowers for pollen. Butterflies were tested only once and were not re-used for the subsequent experiment.

\section{Leaf Shape Experiment}

Following the results of the first experiment, we then wanted to determine whether shape perception also functions in the

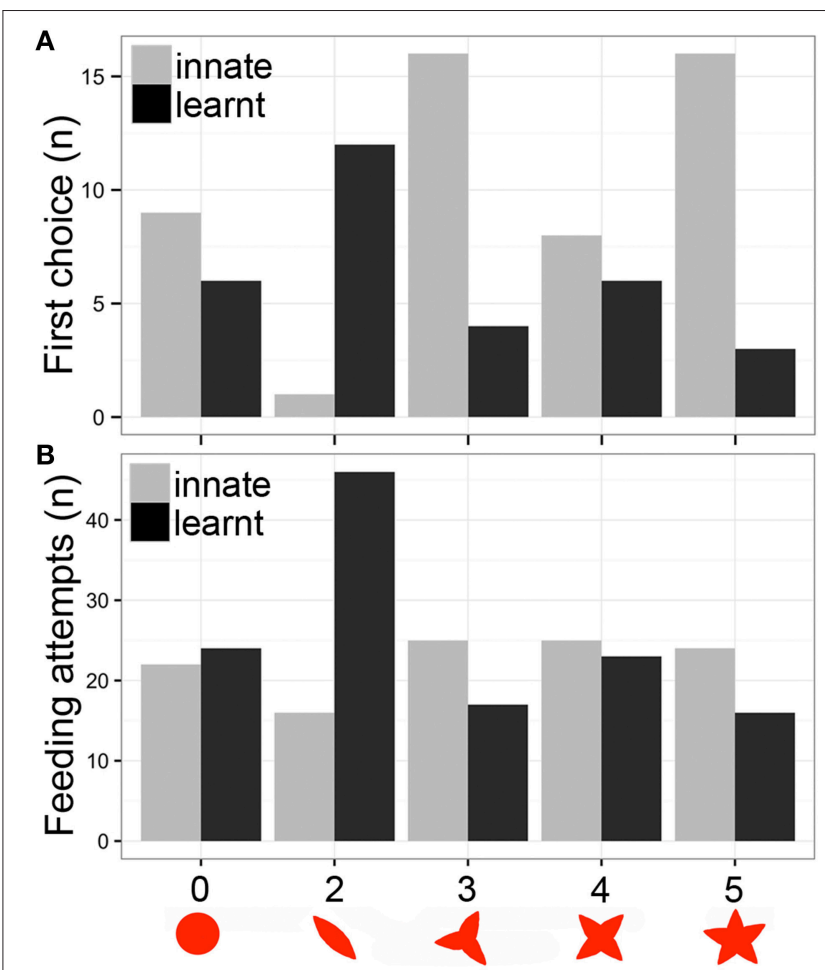

FIGURE 2 | Heliconius butterflies learnt to associate flower shape with a food reward. (A) Number of individuals that selected each shape as first choice. (B) Number of feeding attempts to the five shapes during the assays. The five shapes correspond to no-petals, two, three, four, and five petal artificial flowers. Trials: Innate response, gray bars; Learnt response, black bars.

choice of plants for oviposition. Two artificial leaf models were constructed from green foam sheet (ethylene-vinyl acetate), one $P$. biflora leaf shape, which is depressed obovate with two lateral lobes, and one non-biflora lanceolate leaf shape (Figure 3). The shapes were generated using real leaves (approx. width $\times$ height and area: biflora $=10 \times 8 \mathrm{~cm}$ and $25 \mathrm{~cm}^{2}$; non-biflora $=$ $6 \times 12 \mathrm{~cm}$ and $21 \mathrm{~cm}^{2}$ ). Four artificial leaves were attached to a metal frame onto which a young $P$. biflora shoot without leaves was also attached ( $\sim 70 \mathrm{~cm}$ high). The shoot was placed in a bottle of water, located on the floor and at the center of the cage. $P$. biflora shoots were used, which is the most common host plant for H. erato in Gamboa. It was anticipated that preference for the leaf shape of this species might be the innate response for this species (Smiley, 1978). The stimulus combination of the green leaf with the real plant shoot odor and taste was shown to be sufficient to stimulate oviposition by Heliconius butterflies.

Adult females were kept in $2 \mathrm{~m}^{3}$ insectaries cages without Passiflora plants. All females were mated prior to the experiments. Females were randomly separated into two different training cages: the biflora shape training with only $P$. biflora artificial leaves, and the non-biflora shape training with only lanceolate artificial leaves. Females were free to lay eggs on the young shoots, which were replaced daily. Eggs were counted and collected every day to confirm that 

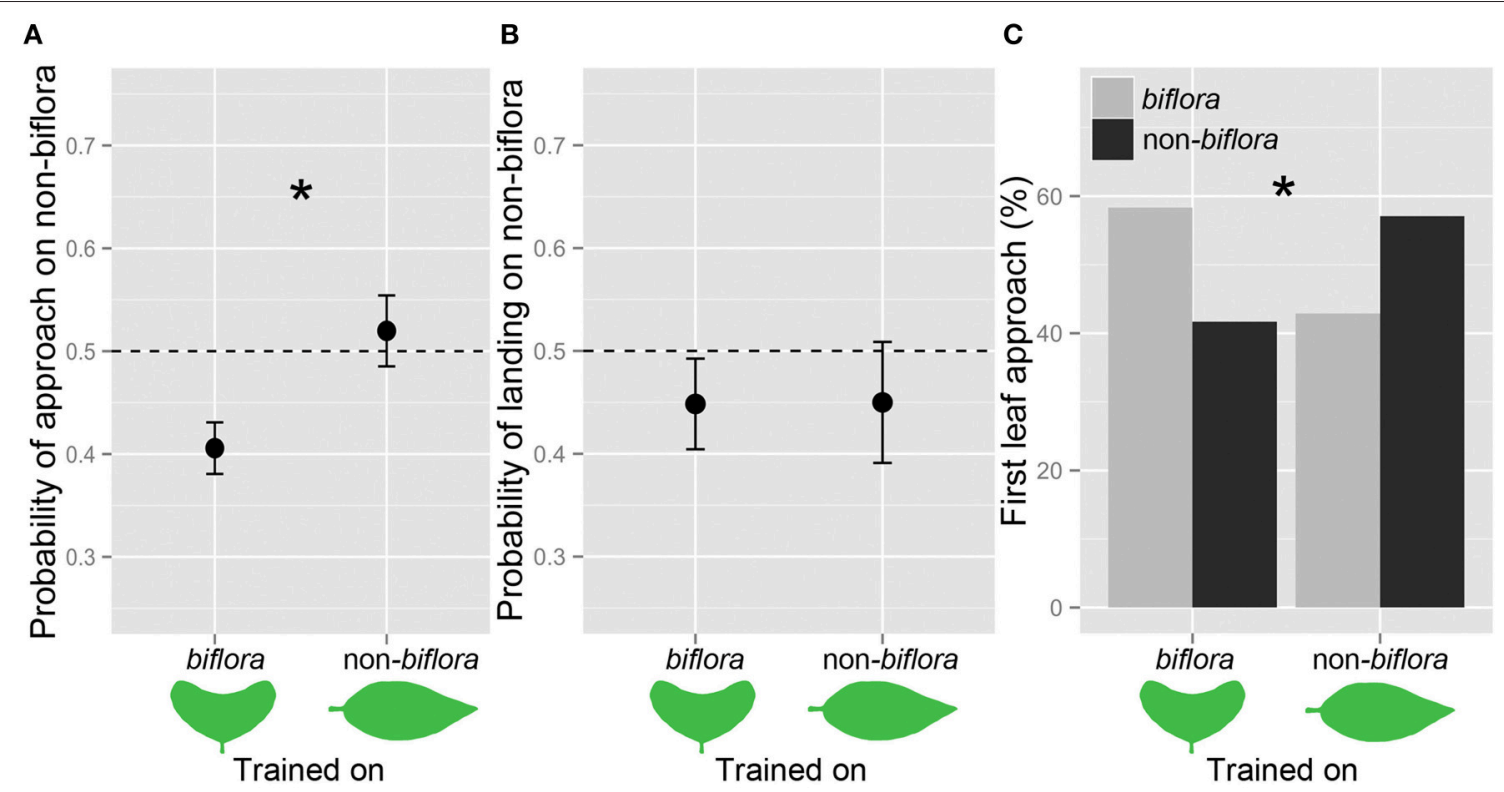

FIGURE 3 | Female butterflies were more likely to approach the leaf shape on which they had been trained. Probabilities of (A) approach and (B) landing on the leaf shapes (mean \pm SE). (C) Proportion of first leaf approach: Biflora, gray bars; Non-biflora, black bars; and ${ }^{\star} P<0.05$.

females were actively laying eggs on the shoots with artificial leaves.

The females were kept in the training cage for a minimum of 8 days, and then moved to a cage without plants for 2 days. Next, a choice experiment was performed, presenting a single focal female with a choice between two leaf shapes, biflora and nonbiflora artificial leaves in the same set up as the training period, and placed $1 \mathrm{~m}$ apart. The female was observed for $30 \mathrm{~min}$, and the first leaf choice, the number of approaches (flying around the stimulus to within a $15 \mathrm{~cm}$ distance), number of landings and eggs laid on the shoot associated with each leaf shape were recorded. Each individual butterfly was tested twice using this choice experiment, totaling $1 \mathrm{~h}$ of observation. Results from the two trials were combined for analysis.

\section{Statistical Analysis}

All statistical analysis was carried out in R ( $\mathrm{R}$ Core Team, 2015) with multcomp package (Hothorn et al., 2008). In the flower shape analysis, we used a general linear model (GLM) in each trial for first choice (binomial) and number of feeding attempts (individuals as random factor), followed by post-hoc tests for the significance of pairwise comparisons when relevant. We calculated the effect of flower area and perimeter on the number of feeding attempts and first choice. We also calculated the interaction between trial (innate and learnt) and flower shape (zero, two, three, four and five) for first choice and number of feeding attempts. There were no differences in behavior between females and males, so both sexes were considered together in the analyses. In the leaf shape analysis, we used a binomial GLM with prior weights, in which the proportion of successes was the response factor weighted by the total number of approaches, landing and eggs, to test for an interaction between leaf choice (biflora or non-biflora) and training regime (on biflora and nonbiflora). We used a Pearson's Chi-squared test (with simulated $p$-value) for first leaf approach data for given proportions.

\section{RESULTS}

\section{Flower Shape Learning}

We recorded a total of 112 feeding attempts during the innate behavior trial and 126 feeding attempts during the learned behavior trial of 53 butterflies. The results indicate that there was a distinctive preference for certain flower shapes. The butterflies showed a preference for the more flower like patterns, with the two-petal flower chosen significantly less than three and five petals as first choice [2 petals: $z_{(260)}=-2.957, P=0.003$; posthoc: $2-3$ petals, $P=0.023 ; 2-5$ petals, $P=0.022$; Figure $2 \mathrm{~A}]$. In contrast, the number of feeding attempts during the innate trial did not differ significantly [2 petals: $t_{(237)}=-1.285, P=$ 0.2 ; Figure 2B]. Neither area nor perimeter influenced number of feeding attempts [area: $t_{(239)}=0.195, P=0.845$; perimeter: $\left.t_{(239)}=1.189, P=0.236\right]$, but perimeter influenced first choice [area: $t_{(262)}=1.033, P=0.302$; perimeter: $t_{(262)}=3.353, P=$ 0.0009].

We then trained the butterflies on their less preferred two petal shape. After the training period, the frequency of visits to the two petal artificial flower increased from 14 to $36 \%$ of all visits (46/126). The first feeding attempt preference shifted significantly to the two petal model flower $\left[z_{(260)}=2.334, P=\right.$ 0.019; Figure 2A], and number of feeding attempts also differed significantly $\left[t_{(217)}=4.218, P<0.001\right.$; Figure $\left.2 \mathbf{B}\right]$. There was a significant interaction between petals and trials for first choice [2 petals*learnt: $z_{(520)}=3.75, P=0.0001$ ], and for number of feeding attempts [2 petals*learnt: $\left.z_{(485)}=3.446, P=0.0006\right]$. 
In addition, the learnt response in terms of number of feeding attempts was influenced by flower perimeter, but not by area [area: $t_{(219)}=-1.198, P=0.232$; perimeter: $t_{(219)}=-3.185, P$ $=0.0016$ ]. Similar results are seen for the first choice data [area: $t_{(262)}=-0.482, P=0.63$; perimeter: $\left.t_{(262)}=-2.286, P=0.023\right]$.

\section{Leaf Shape Choice}

We trained $12 \mathrm{H}$. erato butterflies on biflora artificial leaves and 14 on non-biflora artificial leaves. There was a significant effect of both leaf shape and trial on approach probability. In addition, there was also a significant interaction between training regime and approach probability, demonstrating evidence for learning. Butterflies experienced with non-biflora leaf models were subsequently more likely to approach the non-biflora leaf shape than butterflies experienced with biflora leaf models [training*approach: $z_{(48)}=2.592, P=0.0095$; Figure 3A]. We also found significant differences for first leaf approach $\left(\chi^{2}=\right.$ $4.147, p=0.041$; Figure 3C). However, the preference for landing did not differ between the two training groups [training ${ }^{*}$ landing: $z_{(48)}=-0.116, P=0.908$; Figure 3B $]$.

Females trained on non-biflora leaves laid $46 \%$ on non-biflora, while females trained on biflora leaves laid $47 \%$ of the eggs on non-biflora. There was therefore no significant difference in eggs laid on the shoots between the two training regimes $\left[z_{(49)}=-0.132, P=0.895\right]$.

\section{DISCUSSION}

Here we have shown for the first time that Heliconius butterflies can use shape cues to search for both flowers and leaves during feeding and oviposition. One explanation for the observed spontaneous preference for three and five petal flower shapes is an innate preference for radial symmetry, which corresponds to the actinomorphic flowers used most commonly by Heliconius (Corrêa et al., 2001). After training, we conditioned individuals to shift their shape feeding preference to an artificial flower with two petals, the least preferred shape initially. Previous studies have shown that conditioned Heliconius butterflies can shift their preference to yellow and green flowers, against their innate preference for orange and red (Swihart and Swihart, 1970). Here we show a similar effect for shape cues. Color is perhaps a more reliable visual cue for finding flowers since it is not affected by the angle of approach, as observed in Monarch butterflies (Cepero et al., 2015). However, shape is a complementary cue and may be important to distinguish objects that are similar in color.

The pipevine swallowtail butterfly, B. philenor, has long been known to use leaf shape in oviposition, in experiments in which the butterflies were trained on both real plants (Papaj, 1986) and artificial leaf models (Rausher, 1978; Allard and Papaj, 1996; Weiss and Papaj, 2003). Here we have provided the first evidence that Heliconius also use shape for leaf detection. Our results therefore support field observations of Heliconius female butterflies visually discriminating different leaves while searching for host plants. The butterflies exposed to lanceolate leaves approach the lanceolate shape more than those exposed to $P$. biflora shape. It is worth noting that our artificial plants did not provide a negative stimulus against laying eggs during the training period, in contrast to the way that the flower shape experiment could provide a negative stimulus in terms of the absence of sugar water. The difference in response of the butterflies to the two leaf shape treatments is therefore the result of a learnt association between leaf shape cue and availability of an oviposition stimulus.

The lack of any significant difference between treatments in egg laying perhaps indicates that shape is not the only clue used to oviposit on host plants. Other cues such as leaf color, plant architecture and plant odor and taste are also likely to be extremely important (Rausher, 1978; Allard and Papaj, 1996). Specifically, in the confined insectary space female butterflies do not have trouble in eventually finding the shoots, irrespective of their associated leaf shape. Thus, once they have found both shoots the optimal strategy for a female is to distribute her available eggs evenly between the two shoots. Nonetheless, in the wild where long distance detection of host plants is likely to be more challenging than in a small insectary cage, it seems likely that leaf shape could play an important role in the location of host plants used by female butterflies.

We can therefore speculate about the potential for this learning behavior to influence the evolution of leaf shape in Passiflora. It has been previously suggested that diversification of leaf morphology might be a response to herbivore pressure (Gilbert, 1975; Rausher, 1978). Three elements of Passiflora leaf morphology may have evolved in response to Heliconius visual perception: mimicry, divergence in leaf shape between species and different adult and juvenile foliage (Gilbert, 1982). Negative frequency dependent selection could favor leaf polymorphism, as an unusual or rare leaf morphology would be more likely to escape the attentions of ovipositing butterflies using shape cues. Our results support this and we suggest that this might be an example of "enemy free space" competition (Jeffries and Lawton, 1984; Brown et al., 1991) between Passiflora plants for survival against Heliconius caterpillars.

Heliconius females can show strong host plant preferences that may not be perfectly aligned with larval food preference and survival (Copp and Davenport, 1978; Smiley, 1978; Kerpel and Moreira, 2005; Silva et al., 2014). The ability to learn to associate new leaf shapes with oviposition sites may allow females to tailor their search image to the local Passiflora community. Specifically, in the case of $H$. erato, there are three important host species in the Gamboa area which have dramatically different leaf shapes, $P$. biflora, $P$. auriculata, and $P$. coriaceae (Merrill et al., 2013). Furthermore, there is considerable variation in all three species both between individuals and between young and old leaves. It seems plausible that visual searching behavior by $H$. erato could play a role both in promoting the coexistence of these three species, and as a selective pressure favoring the evolution and maintenance of within species leaf shape diversity.

The Janzen-Connell hypothesis proposes that interactions between parasites and their host could be a driving force in maintaining plant species diversity (Wright, 2002) and even egg coloration polymorphism (Yang et al., 2010). Here we have demonstrated the potential for behavioral plasticity in animal responses to play a role in maintaining plant species diversity. 
If generalist herbivores commonly learn a "search image" for locally common plant species this could be an important source of negative frequency dependent selection favoring rare plant species. In the highly diverse and complex tropical rainforest environment, such an effect might play a role in maintaining species diversity and in particular in sustaining populations of rare species.

\section{AUTHOR CONTRIBUTIONS}

DD and CJ conceived, planned and designed the study. DD and ML conducted the experiments. DD analyzed the data. DD and CJ wrote the manuscript.

\section{REFERENCES}

Allard, R. A., and Papaj, D. R. (1996). Learning of leaf shape by pipevine swallowtail butterflies: a test using artificial leaf models. J. Insect Behav. 9, 961-967. doi: 10.1007/BF02208982

Anderson, A. M. (1977). Shape perception in the honey bee. Anim. Behav. 25, 67-79. doi: 10.1016/0003-3472(77)90068-9

Apple, J. L., and Feener, Jr., D. H. (2001). Ant visitation of extrafloral nectaries of Passiflora: the effects of nectary attributes and ant behavior on patterns in facultative ant-plant mutualisms. Oecologia 127, 409-416. doi: $10.1007 / \mathrm{s} 004420000605$

Barp, E. A., Soares, G. L. G., Gosmann, G., Machado, A. M., Vecchi, C., and Moreira, G. R. P. (2006). Phenotypic plasticity in Passiflora suberosa L. (Passifloraceae): induction and reversion of two morphs by variation in light intensity. Braz. J. Biol. 66, 853-862. doi: 10.1590/S1519-69842006000500011

Benson, W. W., Brown, K. S. Jr., and Gilbert, L. E. (1975). Coevolution of plants and herbivores: passion flower butterflies. Evolution 29, 659-680. doi: $10.2307 / 2407076$

Blackiston, D., Briscoe, A. D., and Weiss, M. R. (2011). Color vision and learning in the monarch butterfly, Danaus plexippus (Nymphalidae). J. Exp. Biol. 214, 509-520. doi: 10.1242/jeb.048728

Briscoe, A. D., Macias-Muñoz, A., Kozak, K. M., Walters, J. R., Yuan, F., Jamie, G. A., et al. (2013). Female behaviour drives expression and evolution of gustatory receptors in butterflies. PLoS Genet. 9:e1003620. doi: 10.1371/journal.pgen.1003620

Brown, K. S. (1981). The biology of Heliconius and related genera. Annu. Rev. Entomol. 26, 427-456. doi: 10.1146/annurev.en.26.010181.002235

Brown, V. K., Lawton, J. H., and Grubb, P. J. (1991). Herbivory and the evolution of leaf size and shape. Philos. Trans. Biol. Sci. 333, 265-272. doi: 10.1098/rstb.1991.0076

Cepero, L. C., Rosenwald, L. C., and Weiss, M. R. (2015). The relative importance of flower color and shape for the foraging monarch butterfly (Lepidoptera: Nymphalidae). J. Insect Behav. 28, 499-511. doi: 10.1007/s10905-015-9519-z

Connell, J. H. (1971). "On the role of natural enemies in preventing competitive exclusion in some marine animals and in rain forest trees," in Dynamics of Populations, eds P. J. D. Boer and G. Gradwell (Wageningen: PUDOC), 298-312.

Copp, N. H., and Davenport, D. (1978). Agraulis and Passiflora I. control of specificity. Biol. Bull. 155, 98-112. doi: 10.2307/1540868

Corrêa, C. A., Irgang, B. E., and Moreira, G. R. P. (2001). Estrutura floral das angiospermas usadas por Heliconius erato phyllis (Lepidoptera, Nymphalidae) no Rio Grande do Sul, Brasil. Iheringia 90, 71-84. doi: 10.1590/S007347212001000100008

Ehrlich, P. R., and Raven, P. H. (1964). Butterflies and plants: a study in coevolution. Evolution 18, 586-608. doi: 10.2307/2406212

Engler, H. S., Spencer, K. C., and Gilbert, L. E. (2000). Preventing cyanide release from leaves. Nature 406, 144-145. doi: 10.1038/35018159

Estrada, C., and Jiggins, C. D. (2002). Patterns of pollen feeding and habitat preference among Heliconius species. Ecol. Entomol. 27, 448-456. doi: 10.1046/j.1365-2311.2002.00434.x

\section{FUNDING}

Cambridge Trust (UK) and CAPES (Brazil) to DD, and Smithsonian Tropical Research Institute (Panama) to ML supported this study.

\section{ACKNOWLEDGMENTS}

We thank Owen McMillan and the Smithsonian Tropical Research Institute for support while working in Panama; Elizabeth Evans and Oscar Paneso for assistance in the insectaries; and two reviewers for valuable comments on this manuscript.

Gianoli, E., and Carrasco-Urra, F. (2014). Leaf mimicry in a climbing plant protects against herbivory. Curr. Biol. 24, 984-987. doi: 10.1016/j.cub.2014.03.010

Gilbert, L. E. (1971). Butterfly-plant coevolution: has Passiflora adenopoda won the selectional race with heliconiine butterflies? Science 172, 585-586. doi: 10.1126/science.172.3983.585

Gilbert, L. E. (1975). "Ecological consequences of a coevolved mutualism between butterflies and plants," in Coevolution of Animals and Plants, eds L. E. Gilbert and P. H. Raven (Austin, TX: University of Texas Press), 210-240.

Gilbert, L. E. (1982). The coevolution of a butterfly and a vine. Sci. Am. 247, 110-121. doi: 10.1038/scientificamerican0882-110

Hothorn, T., Bretz, F., and Westfall, P. (2008). Simultaneous inference in general parametric models. Biom. J. 50, 346-363. doi: 10.1002/bimj.200810425

Izaguirre, M. M., Mazza, C. A., Astigueta, M. S., Ciarla, A. M., and Ballaré, C. L. (2013). No time for candy: passionfruit (Passiflora edulis) plants down-regulate damage-induced extra floral nectar production in response to light signals of competition. Oecologia 173, 213-221. doi: 10.1007/s00442-013-2721-9

Janzen, D. H. (1970). Herbivores and the number of tree species in tropical forests. Am. Nat. 104, 501-528. doi: 10.1086/282687

Jeffries, M. J., and Lawton, J. H. (1984). Enemy free space and the structure of ecological communities. Biol. J. Linn. Soc. 23, 269-286. doi: 10.1111/j.10958312.1984.tb00145.x

Kerpel, S. M., and Moreira, G. R. P. (2005). Absence of learning and local specialization on host plant selection by Heliconius erato. J. Insect Behav. 18, 433-452. doi: 10.1007/s10905-005-3701-7

Lehrer, M., Horridge, G. A., Zhang, S. W., and Gadagkar, R. (1995). Shape vision in bees: innate preference for flower-like patterns. Philos. Trans. Biol. Sci. 347, 123-137. doi: 10.1098/rstb.1995.0017

Mackay, D. A., and Jones, R. E. (1989). Leaf shape and the host-finding behaviour of two ovipositing monophagous butterfly species. Ecol. Entomol. 14, 423-431. doi: 10.1111/j.1365-2311.1989.tb00944.x

Merrill, R. M., Naisbit, R. E., Mallet, J., and Jiggins, C. D. (2013). Ecological and genetic factors influencing the transition between host-use strategies in sympatric Heliconius butterflies. J. Evol. Biol. 26, 1959-1967. doi: 10.1111/jeb.12194

Nardin, J., and Araújo, A. M. (2011). Kin recognition in immatures of Heliconius erato phyllis (Lepidoptera; Nymphalidae). J. Ethol. 29, 499-503. doi: 10.1007/s10164-011-0272-2

Papaj, D. R. (1986). Conditioning of leaf-shape discrimination by chemical cues in the butterfly, Battus philenor. Anim. Behav. 34, 1281-1288. doi: 10.1016/S00033472(86)80199-3

Rausher, M. D. (1978). Search image for leaf shape in a butterfly. Science 200, 1071-1073. doi: 10.1126/science.200.4345.1071

Rausher, M. D., and Papaj, D. R. (1983). Host plant selection by Battus philenor butterflies: evidence for individual differences in foraging behaviour. Anim. Behav. 31, 341-347. doi: 10.1016/S.0003-3472(83)80052-9

R Core Team (2015). R: A Language and Environment for Statistical Computing. Vienna, Austria: R Foundation for Statistical Computing. Available online at: http://www.R-project.org/

Silva, A. K., Gonçalves, G. L., and Moreira, G. R. P. (2014). Larval feeding choices in heliconians: induced preferences are not constrained by performance and 
host plant phylogeny. Anim. Behav. 89, 155-162. doi: 10.1016/j.anbehav.2013. 12.027

Sinervo, B., and Calsbeek, R. (2006). The developmental, physiological, neural, and genetical causes and consequences of frequency-dependent selection in the wild. Annu. Rev. Ecol. Evol. Syst. 37, 581-610. doi: 10.1146/annurev.ecolsys.37.091305.110128

Smiley, J. (1978). Plant chemistry and the evolution of host specificity: new evidence from Heliconius and Passiflora. Science 201, 745-747. doi: 10.1126/science.201.4357.745

Smiley, J. T. (1985a). Are chemical barriers necessary for evolution of butterflyplant associations? Oecologia 65, 580-583. doi: 10.1007/BF00379676

Smiley, J. T. (1985b). Heliconius caterpillar mortality during establishment on plants with and without attending ants. Ecology 66, 845-849. doi: $10.2307 / 1940546$

Smiley, J. T. (1986). ant constancy at Passiflora extrafloral nectaries: effects on caterpillar survival. Ecology 67, 516-521. doi: 10.2307/1938594

Swihart, C. A. (1971). Colour discrimation by the butterfly, Heliconius charitonius Linn. Anim. Behav. 19, 156-164. doi: 10.1016/S0003-3472(71)80151-3

Swihart, C. A., and Swihart, S. L. (1970). Colour selection and learned feeding preferences in the butterfly, Heliconius charitonius Linn. Anim. Behav. 18, 60-64. doi: 10.1016/0003-3472(70)90071-0

Weiss, M. R., and Papaj, D. R. (2003). Colour learning in two behavioural contexts: how much can a butterfly keep in mind? Anim. Behav. 65, 425-434. doi: 10.1006/anbe.2003.2084
Williams, K. S., and Gilbert, L. E. (1981). Insects as selective agents on plant vegetative morphology: egg mimicry reduces egg laying by butterflies. Science 212, 467-469. doi: 10.1126/science.212.4493.467

Wright, S. J. (2002). Plant diversity in tropical forests: a review of mechanisms of species coexistence. Oecologia 130, 1-14. doi: 10.1007/s0044201 00809

Yang, C., Liang, W., Cai, Y., Shi, S., Takasu, F., Møller, A. P., et al. (2010). Coevolution in action: disruptive selection on egg colour in an avian brood parasite and its host. PLoS ONE 5:e10816. doi: 10.1371/journal.pone.00 10816

Zhang, S. W., Srinivasan, M. V., and Collett, T. (1995). Convergent processing in honeybee vision: multiple channels for the recognition of shape. Proc. Natl. Acad. Sci. U.S.A. 92, 3029-3031. doi: 10.1073/pnas.92.7.3029

Conflict of Interest Statement: The authors declare that the research was conducted in the absence of any commercial or financial relationships that could be construed as a potential conflict of interest.

Copyright (ㄷ 2016 Dell'Aglio, Losada and Jiggins. This is an open-access article distributed under the terms of the Creative Commons Attribution License (CC BY). The use, distribution or reproduction in other forums is permitted, provided the original author(s) or licensor are credited and that the original publication in this journal is cited, in accordance with accepted academic practice. No use, distribution or reproduction is permitted which does not comply with these terms. 